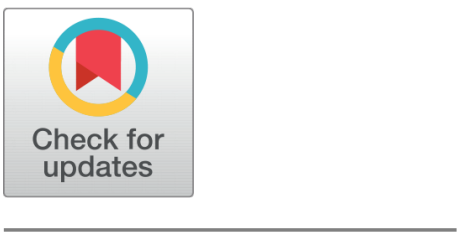

OPEn ACCESS

Received: 15.10 .2020

Accepted: 12.12 .2020

Published: 11.01.2021

Citation: Raval V, Patel A (2021) Narrowband aperture coupled waveguide to microstrip transition for space applications. Indian Journal of Science and Technology 14(1): 33-45. https://doi.org/ 10.17485/IJST/v13i1.1848

* Corresponding author.

Tel: +091-745255229

ravalvidhi69@gmail.com

Funding: None

Competing Interests: None

Copyright: @ 2021 Raval \& Patel. This is an open access article distributed under the terms of the Creative Commons Attribution License, which permits unrestricted use, distribution, and reproduction in any medium, provided the original author and source are credited.

Published By Indian Society for Education and Environment (iSee)

ISSN

Print: 0974-6846

Electronic: 0974-5645

\section{Narrowband aperture coupled waveguide to microstrip transition for space applications}

\author{
Vidhi Raval ${ }^{1 *}$, Amit Patel ${ }^{2}$ \\ 1 PhD Scholar, Charusat University, CSPIT, Changa, Anand, 388421, Gujarat, India. Tel.: +091- \\ 745255229 \\ 2 Assistant Professor, Charusat University, CSPIT, Changa, Anand, 388421, Gujarat, India
}

\section{Abstract}

Background/Objectives: To design, analyze and fabricate aperture coupled waveguide to microstrip transition for Ka-Band where energy is coupled through slot in ground plane and a metal patch placed over the substrate. Methods: Impedance matching approach has been adopted for transition design. Microstrip line is inserted into the waveguide through aperture acting as a probe. Followed by inductive line and transformer line for impedance translation between waveguide and microstrip line. Waveguide transition has been designed using Ansoft High Frequency Structure Simulator (HFSS) full-wave EM simulator. Findings: Designed transition shows return loss performance better than $15 \mathrm{~dB}$ and insertion loss better than $0.5 \mathrm{~dB}$ for back to back configuration over a frequency band of $34-36 \mathrm{GHz}$. Transition is fabricated on RT5580 Duroid substrate $\left(\epsilon_{r}=2.2\right)$ with substrate thickness $0.254 \mathrm{~mm}$. Measured results show return loss better than $25 \mathrm{~dB}$ and insertion loss less than $1 \mathrm{~dB}$ over a frequency band of $34-36 \mathrm{GHz}$. Table 2 shows comparison of present design with previously reported designs in terms of performance. Novelty/Applications: Comparison of the presented transition shows superior performance to previously reported transition designs in terms of transition bandwidth and insertion loss. Aperture coupled transitions can be widely used for space applications where hermetic sealing is required and it saves extra effort for sealing. Certain RF circuit applications require narrowband waveguide transitions to attain required performance, in this case aperture coupled transition can be a good option and its integration with RF circuits is also easy. Fabricated transition design results show good agreement with simulated results so it can be concluded that design is tolerant to fabrication errors. Transition has been fabricated using standard PCB process so production of such transition can be done easily without requirement of any special facility for fabrication.

Keywords: Aperture coupled transition; waveguide; microstrip; kaBand; hermetically sealed 


\section{Introduction}

In past few decades, millimeter wave frequencies have been major attraction to lot of researchers due variety of applications in various fields like detection of objects ${ }^{(1)}$, remote sensing ${ }^{(2)}$ and astronomy ${ }^{(3)}$. At millimeter and sub-millimeter wave frequencies waveguides are often used as interconnect to RF subsystems like Low Noise Amplifiers (LNA), filters, mixers, etc., as it offers low propagation losses and high-power handling capability. Thus, Waveguide to microstrip transitions have become a major component in millimeter wave systems. Waveguide transitions can be realized using two concepts either by impedance matching or by mode conversion techniques. Inline and Ridge waveguide transition are realized using mode conversion techniques. Aperture coupled and transversal transitions are implemented by applying impedance matching technique.

Choice of waveguide transition technique for implementation depends on the type of applications. Ridge waveguide transitions can be used in applications where low propagation loss is intended. On other hand applications where size is a constraint inline transitions can be better option. Transversal transitions can be used in broadband applications whereas aperture coupled transition can be used where narrow band operation is required

Simple transition from microstrip to waveguide using aperture coupled patch was introduced in $1992^{(4)}$. Proximity feeding technique is employed for energy coupling between microstrip lines via slot in ground plane to metal patch element placed on an additional substrate. However, experimental results show narrowband performance due to smaller patch length. Aperture coupled transition design does not require back short so application where space is constraint and waveguide is required at backplane of circuit such transition can be used for implementation. Aperture coupled transition offer remarkable advantage in space constraint applications, as it does not require back short.

Transition design for $\mathrm{W}$ band frequencies has been presented ${ }^{(5)}$ where increase in bandwidth is achieved by moving patch element into waveguide wall resulting increase in distance from feed point. Whereas drawback of this design it added complexity in fabrication and assembly of transition. Based on the experimental results of design presented in ${ }^{(6)}$ shows the presence of EM (Electromagnetic) radiation on top of circuit which in turn reduces coupling of energy between microstrip line and waveguide. This is the major drawback of aperture coupled waveguide transition which occurs due to bidirectional nature of radiation propagating from slot aperture. Back radiations can be reduced by using slot in ground plane of microstrip in order to couple energy between microstrip line and waveguide as presented in ${ }^{(7)}$. In this design an additional second substrate with certain thickness covers aperture inside the waveguide and it works as quarter wave transformer for matching impedance between waveguide and microstrip line. Experimental results presented in this paper show reduction in back side radiations. Another approach presented in ${ }^{(8)}$ to reduce back side radiation is using CPW (Coplanar Waveguide) instead of microstrip line. From experimental results it can be seen that reduction in backside radiation occurs by aligning of feed structure, but the drawback of such design is reduction in pass band and frequency shift.

Designing of rectangular waveguide transition at higher frequency, mechanical tolerances becomes an issue. In such scenario, transition should consist of minimum parts and preferably a single substrate in order to make transition design more robust against fabrication and assembly tolerances. Design presented in ${ }^{(9)}$ provides solution to few of these aspects by analyzing coupling mechanism between patch element and microstrip line. Similar approach has been presented in this present article where coupling mechanism has been exploited using cavity model for patch antenna using matching element. Simulations have been carried out to optimize the patch element length that controls generation of higher modes.

Another technique ${ }^{(10)}$ where one side of substrate cover the cross section of waveguide and other side of substrate slot has been defined, coupling between waveguide and microstrip line is employed using quarter wave transformer as a matching element.

This structure offers benefits of easy fabrication and hermiticity. However, the design measurement results show resonating mode. One of the reasons was alumina substrate with high dielectric constant causes resonance. Thus, the transition design presented in this article is designed using duroid substrate that has a lower dielectric constant.

Sensitivity analysis on manufacturing tolerance is presented in ${ }^{(11)}$. Results show that radiating slots and misalignment with waveguide center line are reason for reduction in energy coupling and errors in quarter wave transformer line causes impedance mismatch. Based on this study, simulations were carried out for optimizing various parameters affecting the performance of the transition that has been discussed in section 4 of this article.

An improved version of slot coupling was presented in ${ }^{(12)}$, where a half wave transformer resonant slot aperture couples energy between waveguide and microstrip by shielding with periodic structure to suppress backside radiation from slot in offer to avoid coupling of parallel modes by cap packaging. Design shows improved performance but increases manufacturing complexity.

Article presented in ${ }^{(13)}$ shows inline microstrip to waveguide transition based on chebyshev transformer implemented in gap waveguide technology. But the issue with the design is fabrication errors can cause propagation of higher modes. SIW to microstrip transition is presented using LTCC technology ${ }^{(14)}$ in which broadband response has been achieved using matching 
element. But experimental results show higher radiation which causes low energy coupling which in turn causes higher insertion loss.

Gap waveguide-based design has been presented ${ }^{(15)}$ to eliminate higher modes by using bed of nails. Drawback of such design is waveguide height lower than $0.6 \mathrm{~mm}$ can only be used otherwise second order modes propagation may occur. To address this issue design has been modified by adding ridge to suppress higher order modes. Design presented in ${ }^{(16)}$ shows transversal transition design for sub-millimeter frequencies where higher mode suppression along microstrip line has been done by designing structure for shielding. Design presented is simple and easy to fabricate. Aperture coupled transition has been presented in ${ }^{(17)}$. High coupling has been achieved using quarter wave transformer line from center of aperture. However, the drawback of this design is size of aperture needs to be very small in order to avoid the coupling of higher modes between SIW and microstrip line. Transversal transition with new impedance transformer structure has been proposed in ${ }^{(18)}$. Higher flexibility in matching is offered due to transformer element but drawback of design is that performance highly depends on fabrication tolerances.

Based on the above study transition design presented in this letter addresses major drawbacks of aperture coupled transition those are backside radiation and higher modes propagation. Therefore, transition is designed using a matching element and quarter wave transformer line which is used as matching impedance between waveguide and microstrip line. Moreover, the transition structure is simple and compatible with conventional low-cost PCB process. For demonstration of this work a prototype of back-to-back waveguide transition is implemented and measured. The measurement results show good agreement with simulated results.

\section{Design and numerical investigation}

Design presented in this paper is a proximity coupled waveguide transition. Entire transition has been designed on a single substrate and substrate is attached to waveguide. Such waveguide transitions are easy to fabricate and assemble. The conductor pattern consists of a patch on bottom layer of the transition and probe at the upper side of dielectric substrate. Dielectric substrate used for design is RT5880 with dielectric constant 2.2 and loss tangent of 1E-04. Substrate thickness 0.254 mm. Rectangular patch on the lower side is surrounded by grounding vias. Aperture is surrounded by grounding via to connect surrounding ground and waveguide short electrically.

The microstrip line acting as probe is inserted into the waveguide. Probe with length I is inserted and it overlaps the round patch as shown in Figure 1. Mode conversion from Quasi TEM to TE is shown in Figure 2. Microstrip line supports Quasi TEM mode and waveguide supports TE10 mode. Low loss waveguide transitions can be realized utilizing highly efficient TM10 mode as intermediate mode which means mode conversion from Quasi TEM to TM10 followed by mode conversion from TM10 to TE10. Such transition can be achieved using rectangular patch element as rectangular patch which supports TM10 mode. Length of Probe inserted acting as a matching element controls the frequency at which TM01 mode resonates. Back-toBack configuration for waveguide transition is shown in Figure 3. Vias have been used in order to prevent backside radiation and prevent lateral radiation leakage. The basic characteristics of aperture coupled transition is that they have a narrow operating band which is quite advantageous in few applications.
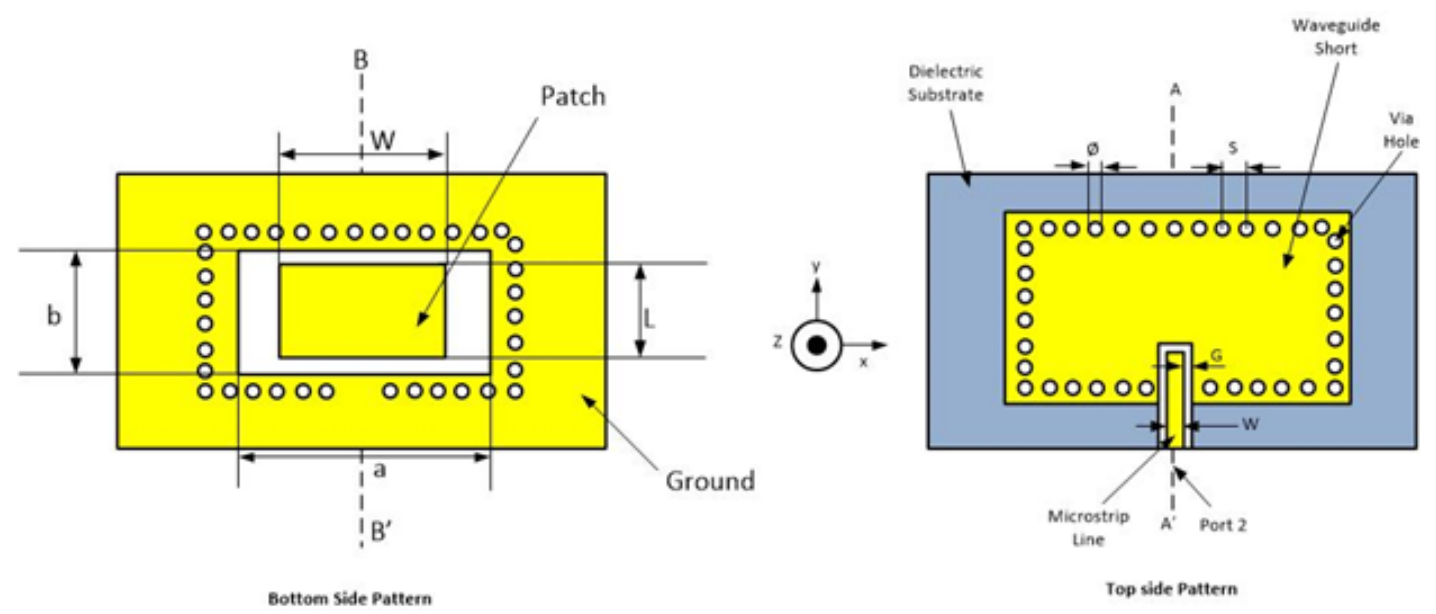

Fig 1. Detailed parameter for aperture coupled transition 


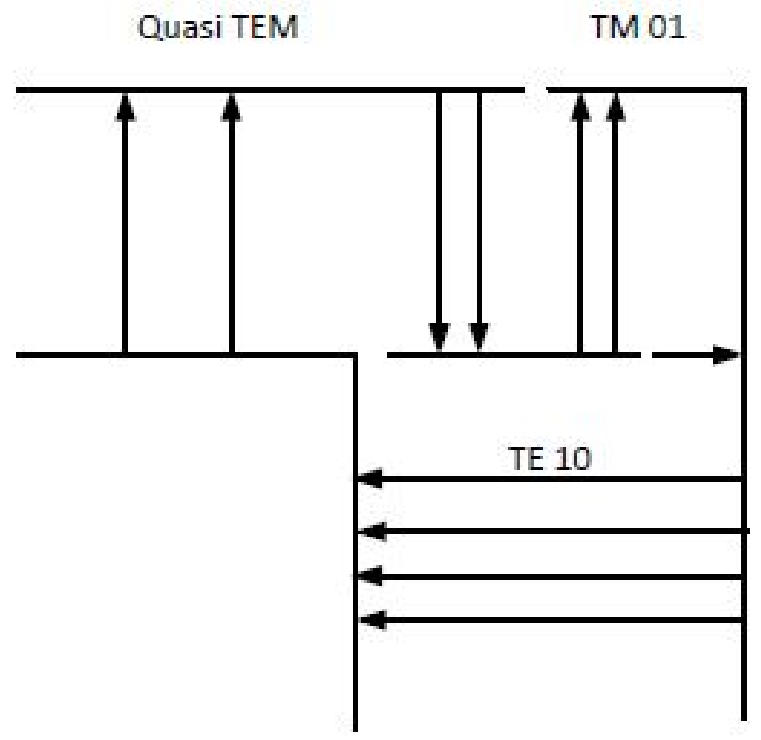

Fig 2. Mode conversion for waveguide transition

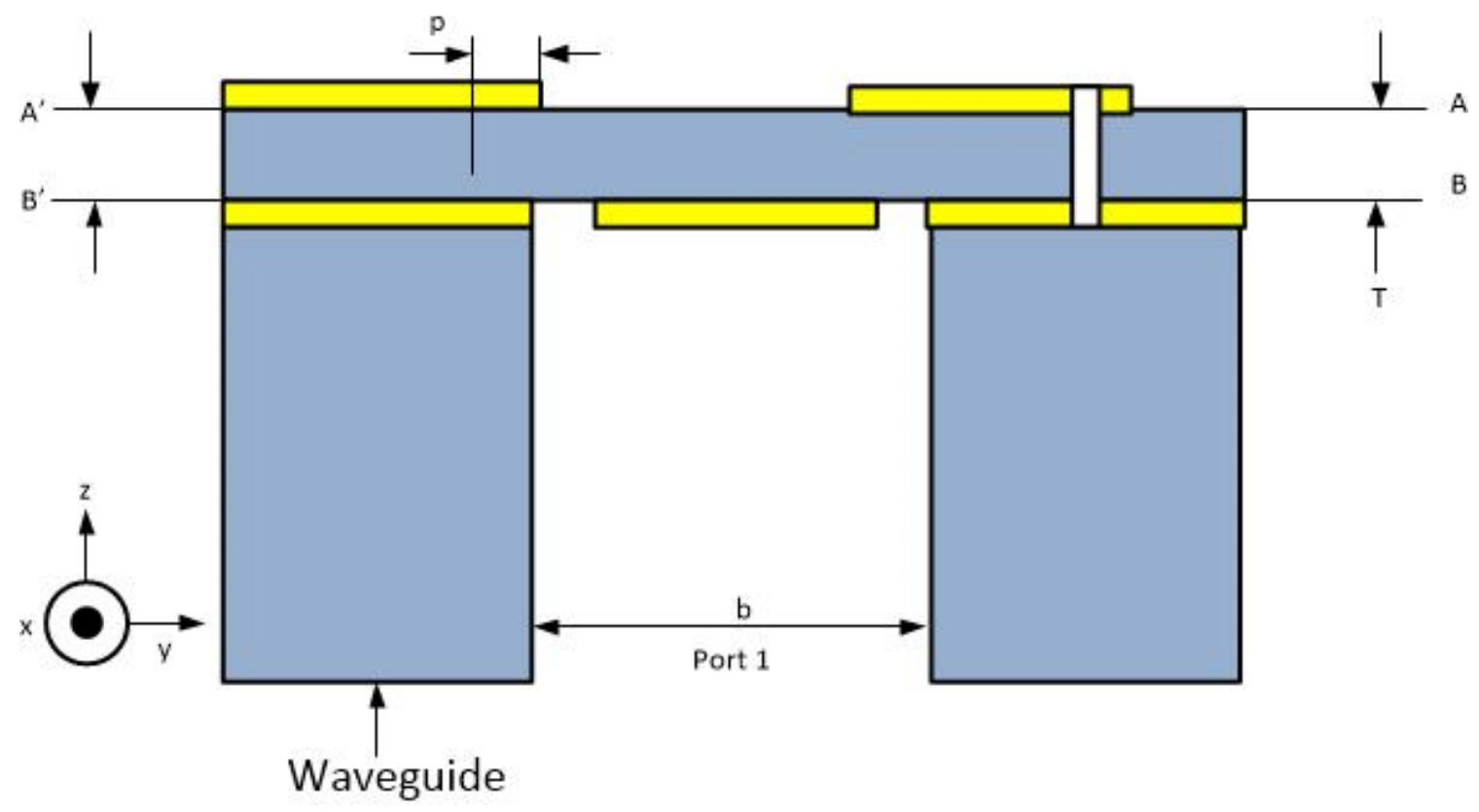

Fig 3. Back to back configuration for waveguide transition

\section{Optimization of Bandwidth}

Various parameters of waveguide transition were investigated in order to find the optimizing parameter for bandwidth. Cavity model used for patch antennas and dyadic Green's model for waveguide is shown in Figure 4. L and W are the effective length and width of patch respectively. 


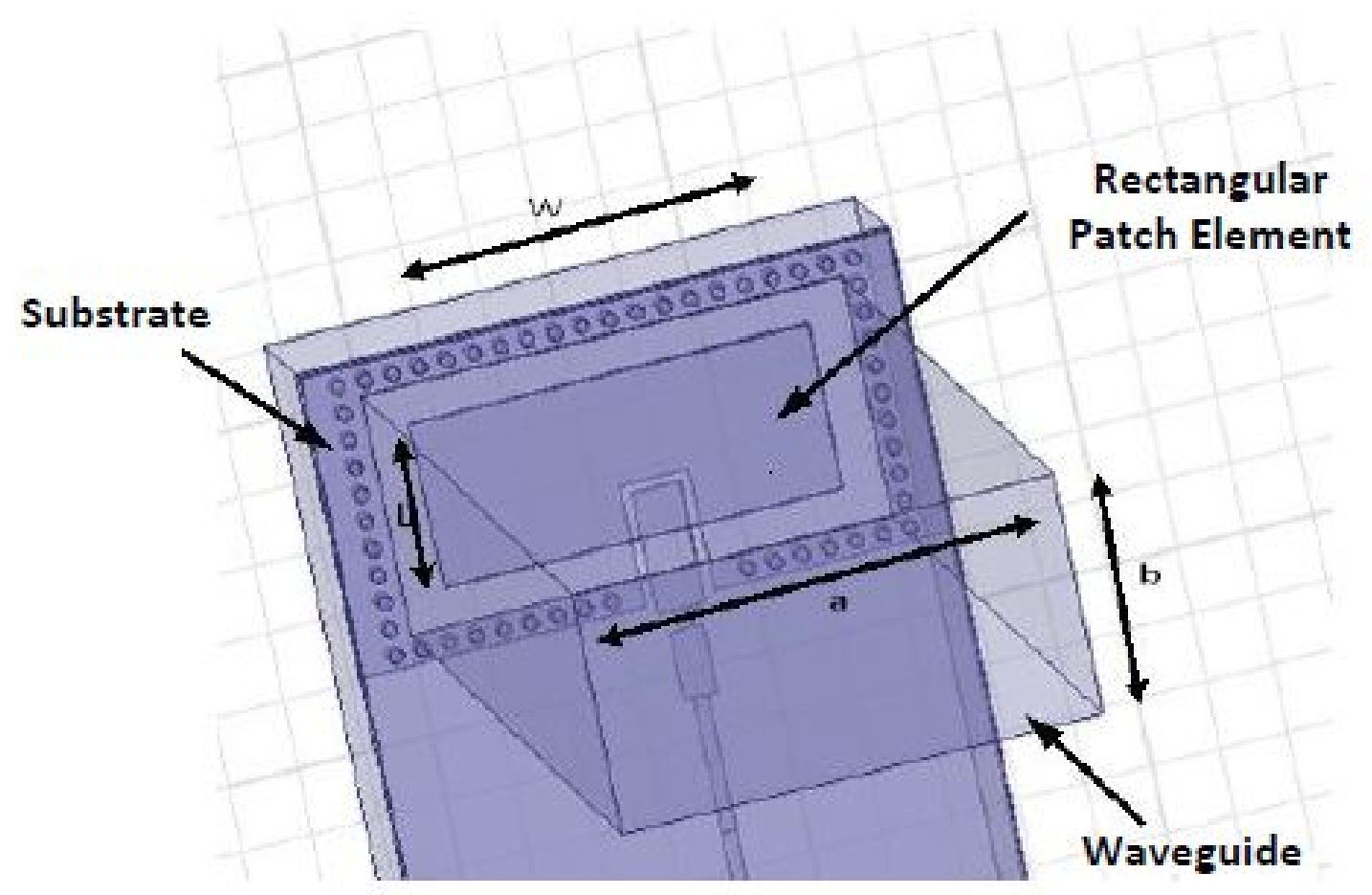

Fig 4. Aperture coupled waveguide to microstrip transition

The quality factor $Q_{e}$ for patch element can be given by:

$$
\frac{1}{Q e}=\frac{1}{Q w g}+\frac{1}{Q c}+\frac{1}{Q d}
$$

where $Q_{w g}$ is quality factor power transmitter into the waveguide $Q_{c}$ is quality factor of conductor losses

$Q_{d}$ is quality factor of dielectric losses

Quality factor of $Q_{w g}$ as per cavity model and dyadic model can be given as follows ${ }^{(8)}$

$$
Q_{w g}=\frac{15 \omega \pi \varepsilon_{0} \varepsilon_{e} L}{2 * W * t} \frac{1}{\sqrt{1-\left(\frac{\lambda g}{2 a}\right)^{2}}} \frac{1}{\left(\frac{\sin \left(\frac{W_{e \pi}}{2 a}\right)}{\left(\frac{W_{e \pi}}{2 a}\right)}\right)^{2}}
$$

Where $\omega$ is angular frequency

$\varepsilon_{0}$ is absolute Permittivity

$\lambda_{g}$ is guided wavelength

Maximum bandwidth can be calculated by relation between quality factor $Q_{e}$ and effective width $\mathrm{W}$ which can be stated in equation (3)

$$
\mathrm{W}=\frac{2 a c}{\pi}
$$

Where $c$ is a constant value 1.666 
For minimum quality factory $Q_{e}, Q_{w g}$ can be calculated as follows

$$
Q_{w g} \mid w=\frac{2 a C}{\pi}=\frac{15 \omega \pi \varepsilon_{0} \varepsilon_{e} L * b}{4 t} \frac{1}{\sqrt{1-\left(\frac{\lambda g}{2 a}\right)^{2}}} \frac{C}{(\sin c)^{2}}
$$

The bandwidth increases with increasing value of a, while effective width $\mathrm{W}$ is kept constant if broad bandwidth is required.

Based on above equations it can be concluded that broadband response can be achieved by increasing the relative permittivity $\varepsilon_{e}$ and substrate thickness. Design presented in this paper was optimized for narrow band performance. Thus, thinner substrate with low relative permittivity has been selected for the design.

Design of transition is done using High Frequency Structure Simulator (HFSS) full wave EM simulator. Simulated results show return loss better than $15 \mathrm{~dB}$ and insertion loss less than $2 \mathrm{~dB}$ over the frequency band of 34-36 GHz as shown in Figure 5 .

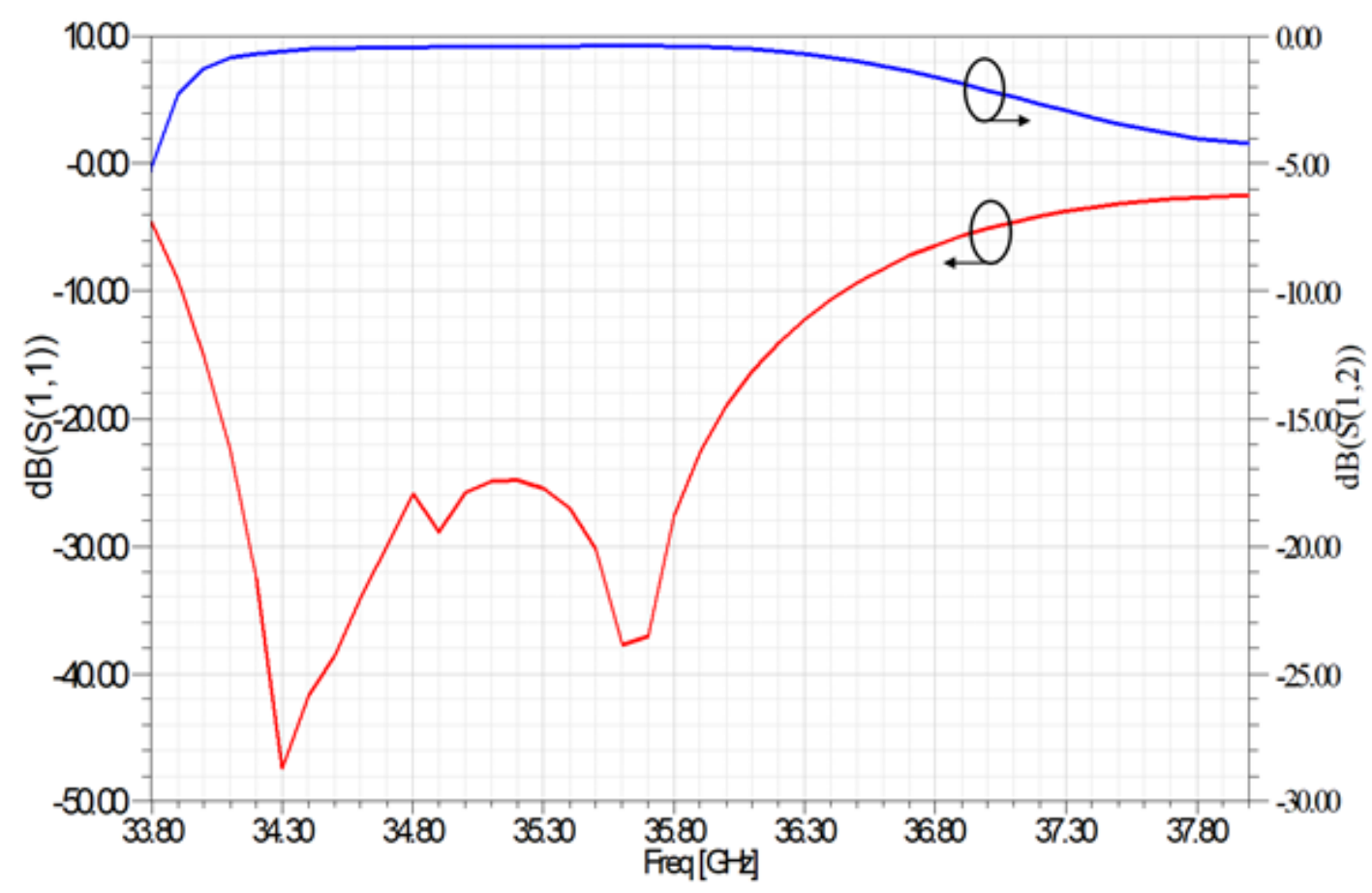

Fig 5. Transmission characteristics of waveguide to microstrip transition

\section{Optimization}

Bandwidth of aperture coupled transition depends on various design parameters like length of broad wall and narrow wall, substrate thickness, permittivity and patch length. If the length of broad wall is increased, bandwidth increases while conversely increasing the length of narrow wall causes reduction in bandwidth. Bandwidth of design greatly depends on substrate characteristics like permittivity and thickness of substrate. Narrowband response can be achieved with thin substrate and lower permittivity. Selection of substrate thickness and permittivity has been done considering the design development for narrowband response and therefore is designed with RT5880 duroid substrate with thickness $0.254 \mathrm{~mm}$ and permittivity 2.2 .

Lower resonant frequency of waveguide transition depends on length of patch. Lower resonant frequency can be controlled by length of patch element as shown in Figure 6. Data in Table 1 depicts that the length of patch element does not affect the bandwidth of transition. So if lower modes are to be eliminated than decreasing the length of patch element can help to reduce propagation of lower modes and is shown in Figure 6. Lower patch length higher the resonating frequency. On other hand higher resonant frequency depends on distance between via and broad wall of waveguide. Thus, higher resonant frequency can be controlled using the distance between via and broad wall of waveguide. As the space between via and broad wall increases, resonating frequency shifts towards higher frequencies as shown in Figure 7. 
Table 1. Relationship between bandwidth and transition parameters

\begin{tabular}{lll}
\hline & \multicolumn{1}{c}{ Parameters } & Bandwidth \\
\hline Effective width W of patch element & $\mathrm{W}=\frac{2 a c}{\pi}$ & Maximum bandwidth \\
Waveguide broad wall a & Increased & Increases \\
Permittivity & Decreased & Increases \\
Waveguide narrow wall b & Decreased & Increases \\
Substrate Thickness t & Increased & Increases \\
Patch length $\mathrm{L}$ & Fixed $\lambda / 2$ & No effect \\
\hline
\end{tabular}

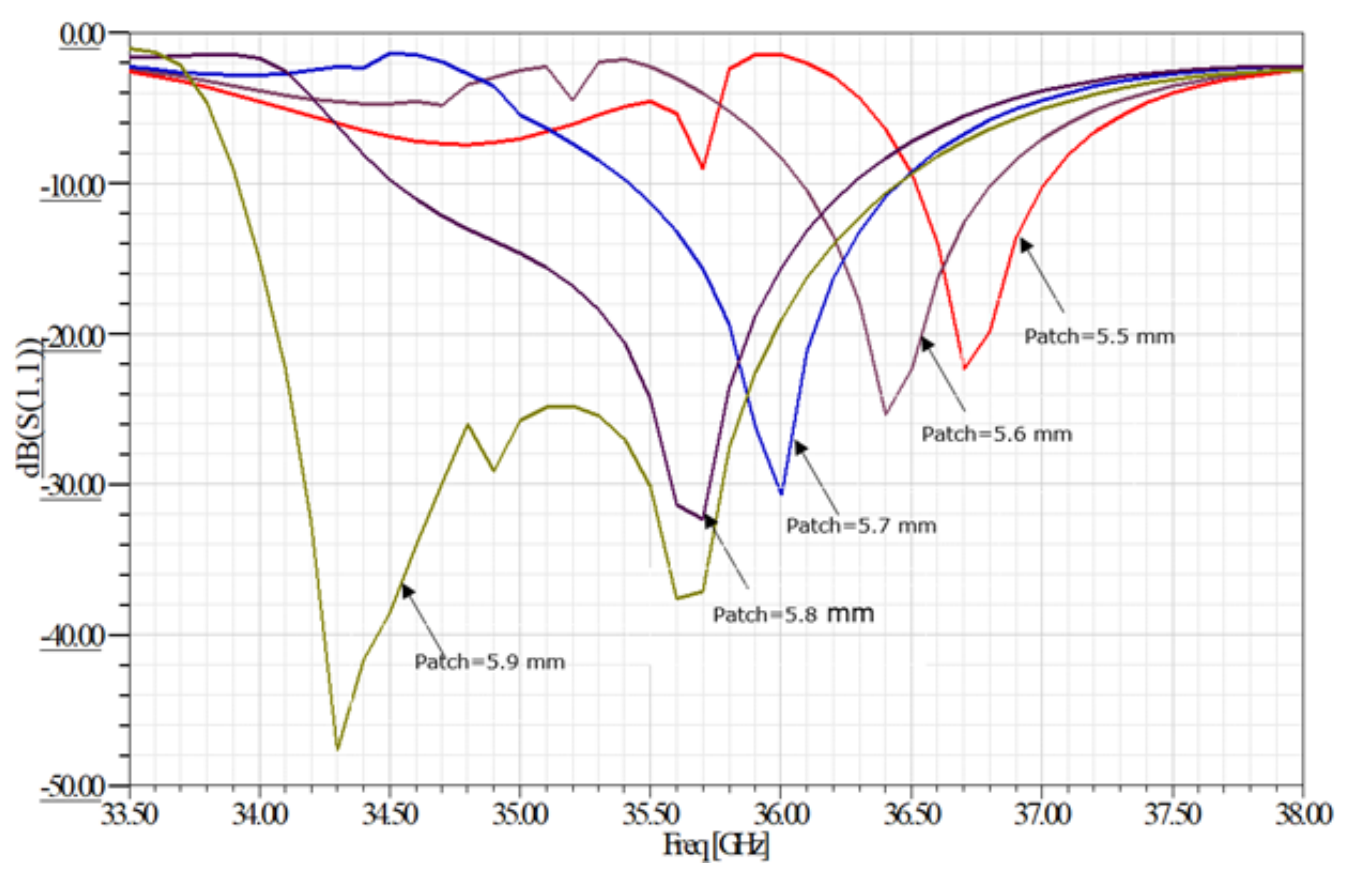

Fig 6. Return loss versus length of patch element variation

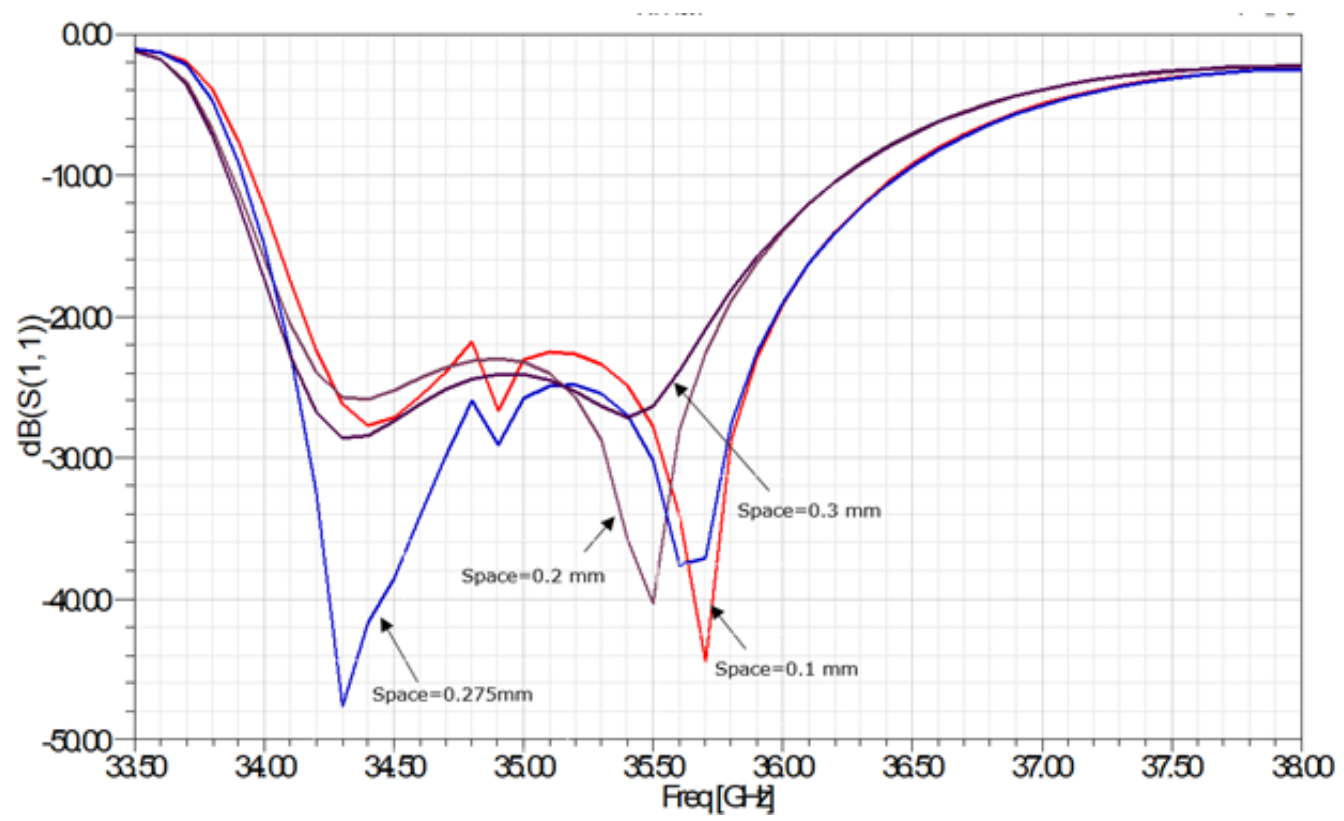

Fig 7. Return loss versus variation in distance between via and broad wall of waveguide 


\section{Impedance Matching}

Impedance matching can be done by inserting microstrip line within rectangular patch. Insertion of probe inside the rectangular waveguide causes reduction in capacitance and increase in inductance between probe and waveguide wall as shown in Figure 8. Another parameter that can be used for impedance matching is $\mathrm{W}$ width of patch element. Resistance can be varied by varying length of patch element. Increase in width causes reduction in resistance as shown in Figure 9.

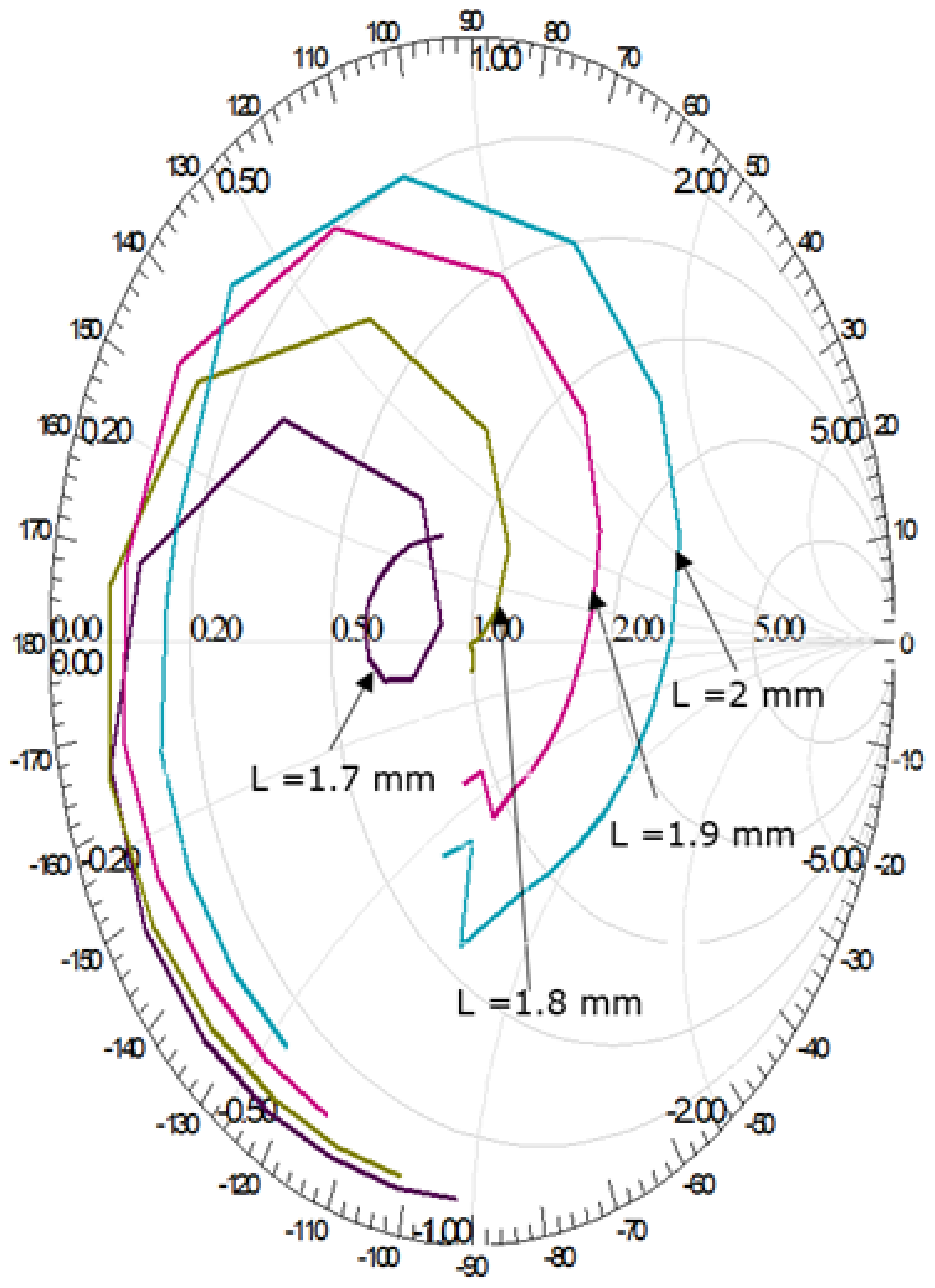

Fig 8. Smith chart showing variation of probe length 


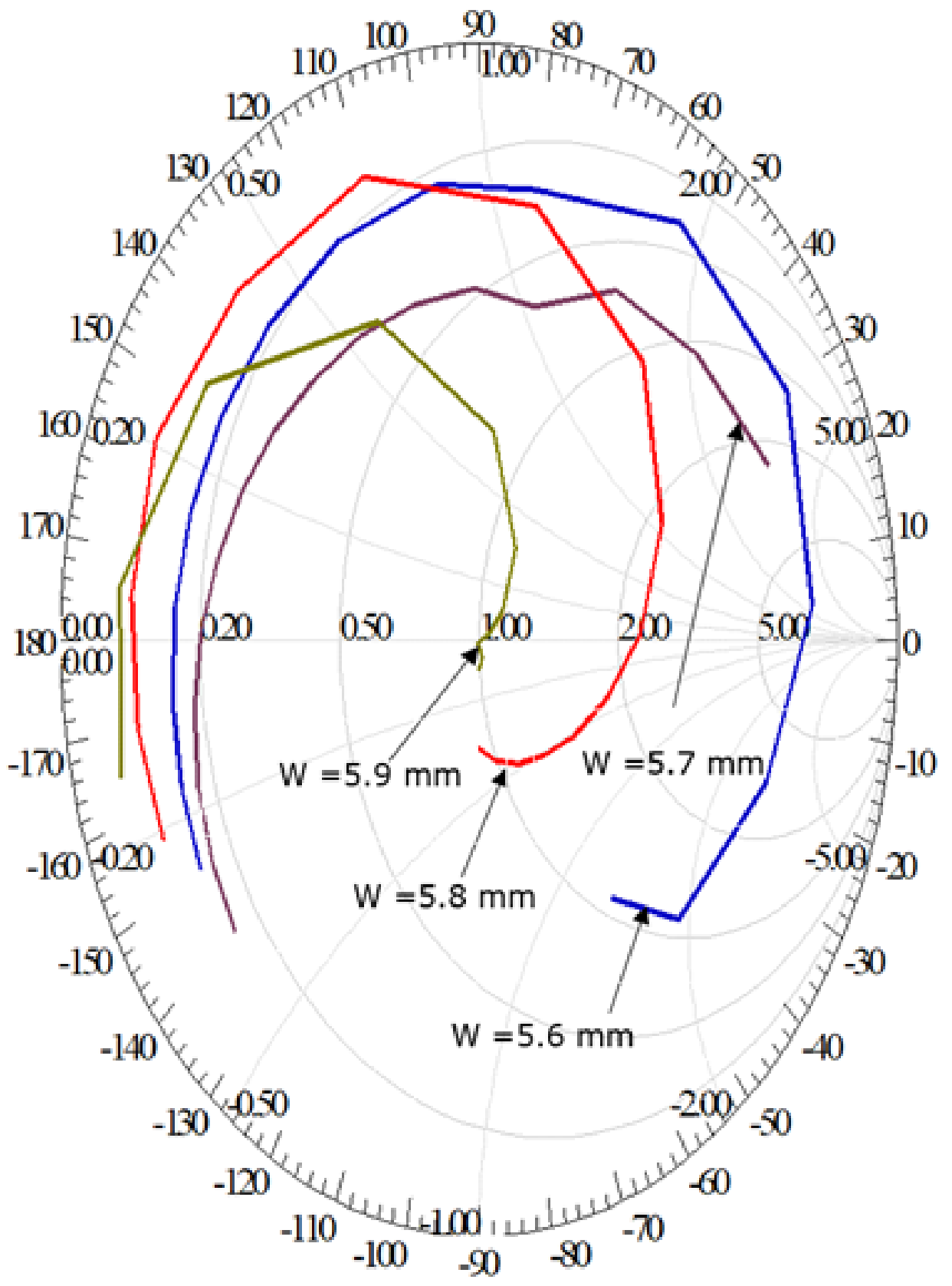

Fig 9. Smith chart showing variation of width of rectangular patch

\section{Fabrication and Measurement}

Transition design presented in this paper was fabricated as shown in Figure 10. Figure 10(a) shows the upper plane of substrate and Figure 10(b) shows the lower section of substrate. Size of transition fabricated is $15 \mathrm{~mm} \times 9 \mathrm{~mm}$. Measurements were carried out using N5244 B keysight microwave network analyzer. Comparison of measured and simulated results is shown in Figures 11 and 12. Good alignment between simulation results and simulation results is observed. The measured return loss for fabricated transition is better than $25 \mathrm{~dB}$ and insertion loss less than $1 \mathrm{~dB}$ over a frequency band of 34 to $36 \mathrm{GHz}$. Surface roughness and fabrication errors resulted in slight discrepancy between simulated and measured insertion loss. Such a superior performance of design is achieved by combination of optimum rectangular patch element width which suppresses higher modes and the probe length being inserted inside the waveguide which increases coupling between microstip line and waveguide. 


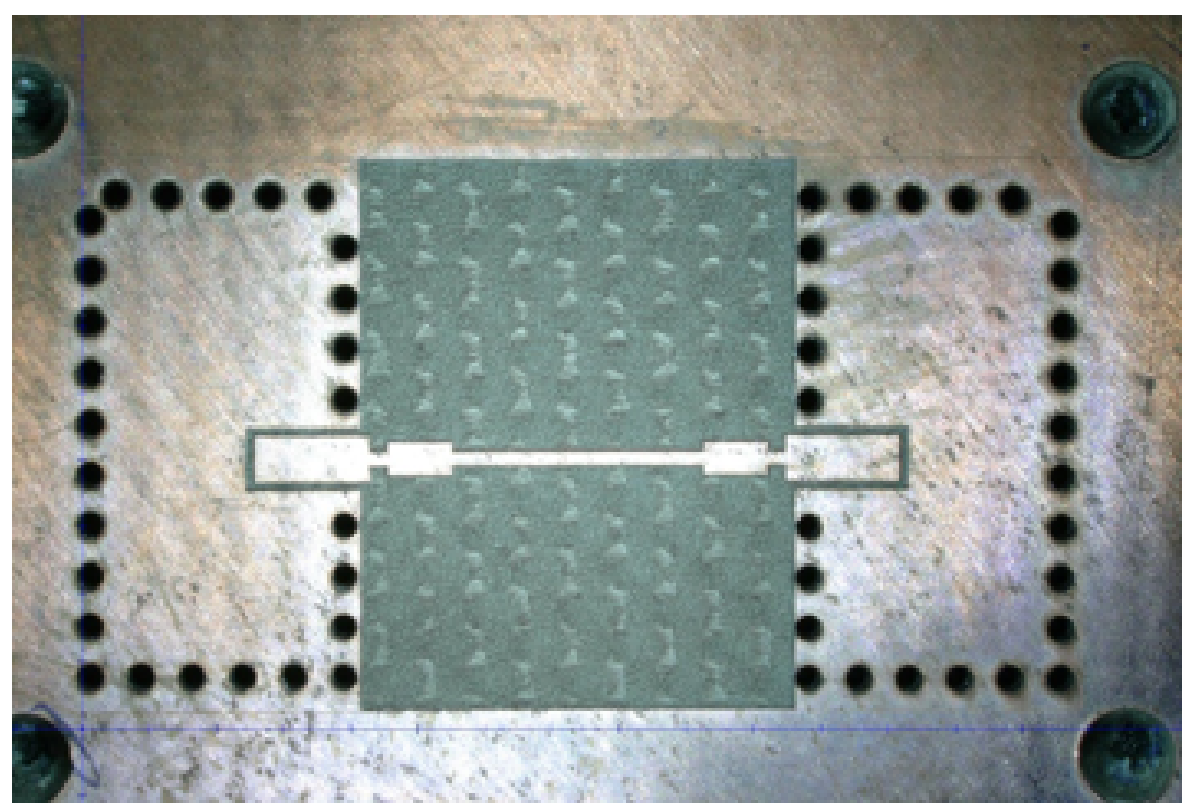

(a)

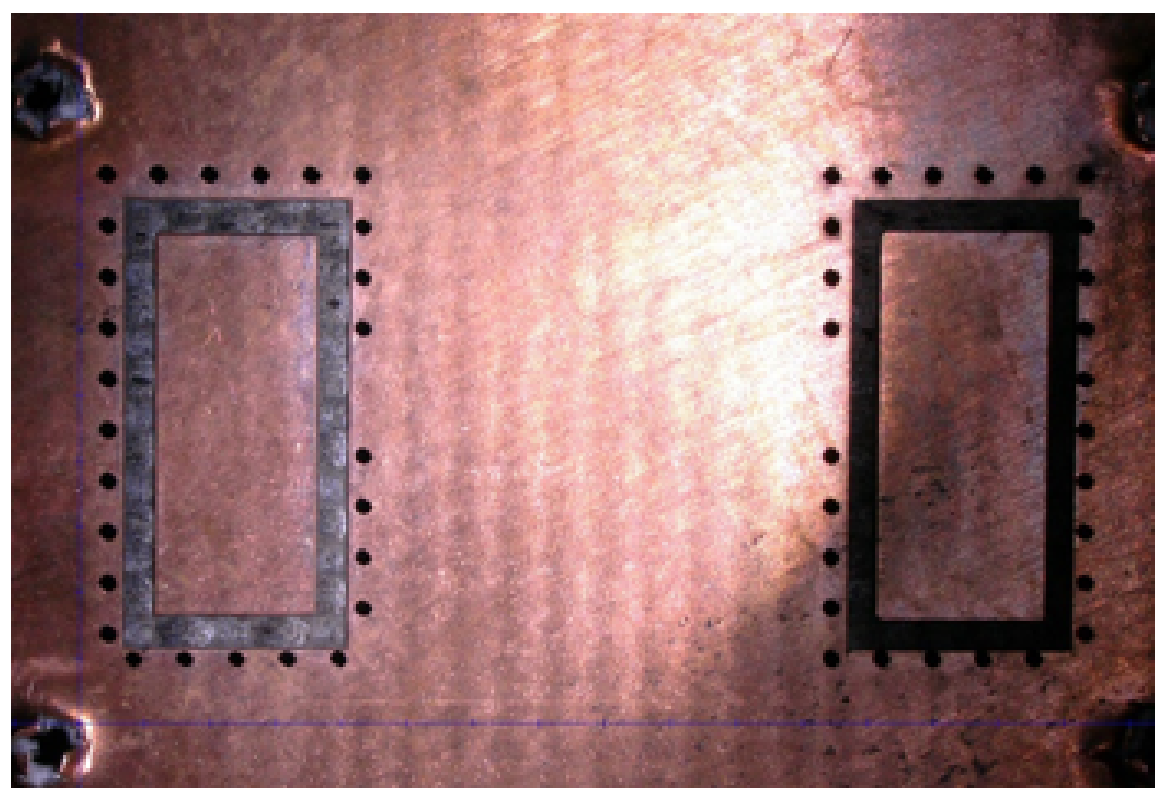

(b)

Fig 10. (a) Upper plane of substrate (b) Lower plane of substrate 


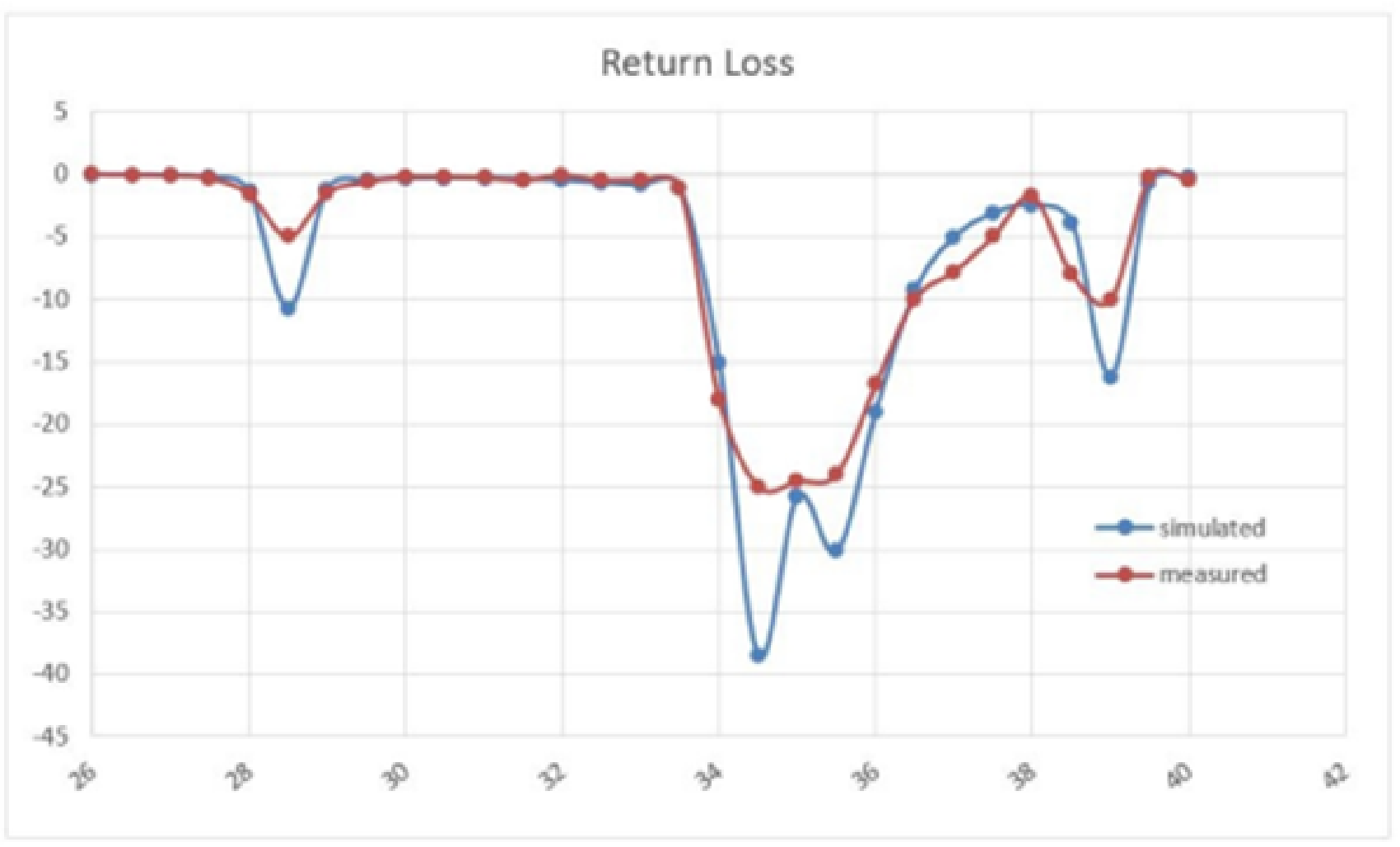

Fig 11. Simulated versus measured results for return loss

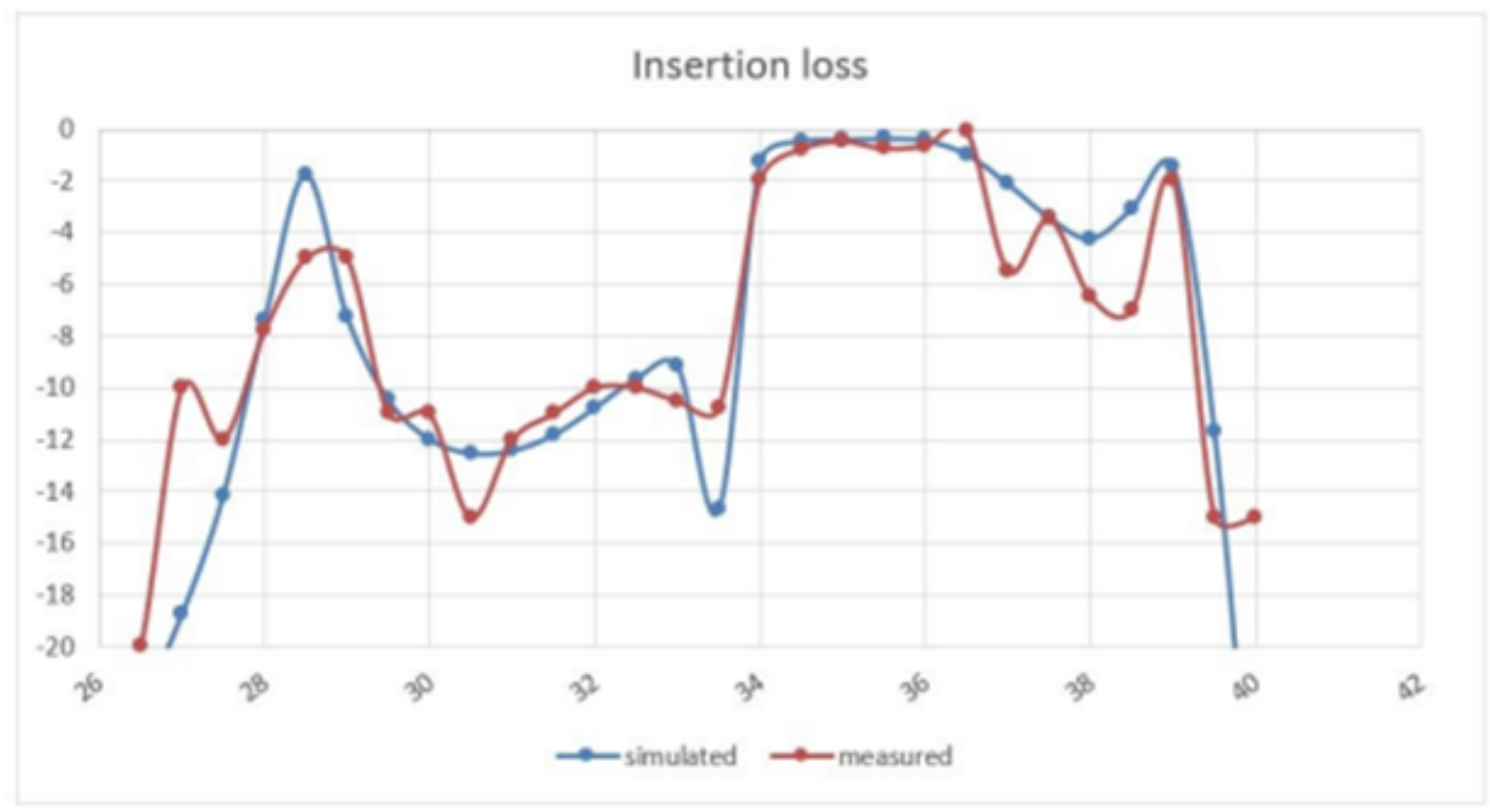

Fig 12. Simulated versus measured results for Insertion Loss 


\section{Comparison}

Structural characteristics and performance of various reported articles has been summarized in Table 2. Design presented in ${ }^{(19)}$ shows broadband performance compared to design in presented in this article as wedge shaped cavity increases the coupling between microstrip line and waveguide. Design presented in ${ }^{(20)}$ shows superior performance in terms of bandwidth compared to present design as higher coupling is achieved as VM strip and aperture together act as ideal transformer and improved coupling efficiency. Present work shows better performance compared to design presented in ${ }^{(21)}$ in terms of return loss performance. Transition design presented in ${ }^{(22)}$ shows comparatively high insertion loss than present design as coupling between waveguide and microstrip line could be maximized if two slots are placed very near to each other but due to fabrication constraint minimum insertion loss achieved was $-4.5 \mathrm{~dB}$. Design presented in [25] shows superior performance than present design in terms of loss as metallized groove technique is used around sidewalls of the rectangular waveguide. Present design shows much lower loss and improved coupling as compared to design presented in [26] over the same bandwidth. Based on comparison with previously reported design, present work considerably shows improved performance in terms of bandwidth, return loss and insertion loss.

Table 2. Comparison of present work with previous works

\begin{tabular}{lllllll}
\hline Reference & Frequency $(\mathrm{GHz})$ & Substrate Thickness $(\mathrm{mm})$ & Substrate $\varepsilon$ & Insertion Loss $(\mathrm{dB})$ & Return Loss $(\mathrm{dB})$ & FBW $(\%)$ \\
\hline$(23)$ & $28-38$ & 0.254 & 2.2 & 0.8 & 13 & 30.3 \\
$(24)$ & $7-13$ & 0.35 & 10.2 & 0.82 & Better than $16 \mathrm{~dB}$ & 37 \\
$(19)$ & $47.6-76.7$ & 0.508 & 2.94 & Less than $1.3 \mathrm{~dB}$ & Better than $12 \mathrm{~dB}$ & 44.8 \\
$(20)$ & $57-82.7$ & 0.254 & 2.2 & Less than $5 \mathrm{~dB}$ & Less than $10 \mathrm{~dB}$ & 37.7 \\
$(21)$ & $26.65-30.20$ & 0.254 & 2.33 & $0.3 \mathrm{~dB}$ & Better than $20 \mathrm{~dB}$ & 12 \\
$(22)$ & $50-70$ & 0.254 & 5.8 & 1.9 & Better than $10 \mathrm{~dB}$ & 8.3 \\
$\begin{array}{l}\text { Present } \\
\text { work }\end{array}$ & $33.5-38$ & 0.254 & 2.2 & Less than $1 \mathrm{~dB}$ & Better than $25 \mathrm{~dB}$ & 14.4 \\
\hline
\end{tabular}

\section{Conclusion}

Design of waveguide transition presented in this study can be used for narrow and wideband applications by varying the design parameters. Optimum width of rectangular patch element for narrowband response has been proposed. Suppression of higher modes generated has also been proposed by optimizing the distance between via and broad wall of waveguide. Optimum combination of patch width and spacing between via and broad wall leads to such improved performance. Simulation and measured results show that such low loss transition can be used practically and can be easily fabricated. Measured results for fabricated design show return loss better than $25 \mathrm{~dB}$ and insertion loss less than $1 \mathrm{~dB}$ over a frequency band of 34-36 GHz for back-to-back waveguide transition.

\section{References}

1) Appleby R, Coward PR, Sinclair GN. Terahertz detection of illegal objects. In: Terahertz frequency detection and identification of materials and objects. Springer. 2007;p. 225-240. Available from: https://doi.org/10.1007/978-1-4020-6503-3.

2) Coward PR, Appleby R. Development of an illumination chamber for indoor millimeter-wave imaging. In: and others, editor. Passive Millimeter-wave Imaging Technology VI and Radar Sensor Technology VII. 2003;p. 54-61. Available from: http://doi.org/10.1117/12.487031.

3) Graauw TD, Helmich FP, Phillips TG, Stutzki J, Caux E, Whyborn ND, et al. The Herschel-heterodyne instrument for the far-infrared (HIFI). Astronomy \& Astrophysics. 2010;518. Available from: http://doi.org/10.1051/0004-6361/201014698.

4) Grabherr W, Menzel W. A New Transition from Microstrip Line to Rectangular Waveguide. In: and others, editor. 22nd European Microwave Conference. 1992. Available from: https://doi.org/10.1109/euma.1992.335862.

5) Grabherr W, Huder WGB, Menzel W. Microstrip to waveguide transition compatible with MM-wave integrated circuits. IEEE Transactions on Microwave Theory and Techniques. 1994;42(9):1842-1843. Available from: https://dx.doi.org/10.1109/22.310597.

6) Shireen R, Shi S, Yao P, Schuetz CA, Macario J, Prather DW. CPW to rectangular waveguide transition on an $\$\{\{\text { LiNbO }\}\}_{-}\{3\} \$$ substrate. IEEE Transactions on Microwave Theory and Techniques. 2009;57(6):1494-1499. Available from: https://dx.doi.org/10.1109/tmtt.2009.2020673.

7) Hyvonen L, Hujanen A. A compact MMIC-compatible microstrip to waveguide transition. IEEE MTT-S International Microwave Symposium Digest. 1996. Available from: https://doi.org/10.1109/mwsym.1996.511077.

8) Simon W, Werthen M, Wolff I. A novel coplanar transmission line to rectangular waveguide transition. IEEE MTT-S International Microwave Symposium Digest. 1998. Available from: https://doi.org/10.1109/mwsym.1998.689369.

9) Iizuka $\mathrm{H}$, Watanabe $\mathrm{T}$, Sato $\mathrm{K}$, Nishikawa K. Millimeter-wave microstrip line to waveguide transition fabricated on a single layer dielectric substrate. IEICE transactions on communications. 2002;85(6):1169-1177. 
10) Iizuka $\mathrm{H}$, Sakakibara $\mathrm{K}$, Kikuma $\mathrm{N}$. Millimeter-Wave transition from waveguide to two microstrip lines using rectangular patch element. IEEE Transactions on Microwave Theory and Techniques. 2007;55(5):899-905. Available from: https://dx.doi.org/10.1109/tmtt.2007.895139.

11) Cavanna T, Franzese E, Limiti E, Pelosi G, Selleri S, Suriani A. FEM-based evaluation of manufacturing tolerances on a millimeter-waves rectangular to coplanar waveguide transition. In: and others, editor. 15th International Conference on Microwaves, Radar and Wireless Communications. IEEE. . Available from: https://doi.org/10.1109/mikon.2004.1356894.

12) Poprawa F, Ziroff A, Ellinger F. A Novel Approach for a Periodic Structure Shielded Microstrip Line to Rectangular Waveguide Transition. In: and others, editor. IEEE/MTT-S International Microwave Symposium. 2007. Available from: https://doi.org/10.1109/mwsym.2007.380572.

13) Zhang T, Li L, Zhu Z, Cui TJ. A Broadband Planar Balun Using Aperture-Coupled Microstrip-to-SIW Transition. IEEE Microwave and Wireless Components Letters. 2019;p. 1-3. Available from: https://doi.org/10.1109/lmwc.2019.2922499.

14) Yakovlev AB, Ortiz S, Ozkar M, Mortazawi A, Steer MB. A waveguide-based aperture-coupled patch amplifier array-full-wave system analysis and experimental validation. IEEE Transactions on Microwave Theory and Techniques. 2000;48(12):2692-2699. Available from: https://dx.doi.org/10.1109/22. 899032.

15) Pérez-Escudero JM, Torres-García AE, Gonzalo R, Ederra I. A gap waveguide-based compact rectangular waveguide to a packaged microstrip inline transition. Applied Sciences. 2020;10(14). Available from: https://dx.doi.org/10.3390/app10144979.

16) Vidhi R, Patel A. Novel Design of waveguide to Microstrip Transition at Millimeter -Wave Frequencies. International Journal of Advanced Science and Technology. 2020;29(04):6645-6665.

17) Zhang T, Li L, Zhu Z, Cui TJ. A Broadband Planar Balun Using Aperture-Coupled Microstrip-to-SIW Transition. IEEE Microwave and Wireless Components Letters. 2019;p. 1-3. Available from: https://doi.org/10.1109/lmwc.2019.2922499.

18) $\mathrm{Xu} \mathrm{W}$, Liu F, Xu H. A novel ultra-wideband waveguide-to-microstrip transition for millimeter-wave applications. AIP Advances. 2016;6(10). Available from: https://doi.org/10.1063/1.4964492.

19) Mohamed I, Sebak AR. Broadband transition of substrate-integrated waveguide-to-air-filled rectangular waveguide. IEEE Microwave and Wireless Components Letters. 2018;28(11):966-968. Available from: https://dx.doi.org/10.1109/lmwc.2018.2871330.

20) Aliakbarian H, Enayati A, Vandenbosch GAE, Raedt WD. Novel low-cost end-wall microstrip-to-waveguide splitter transition. Progress In Electromagnetics Research. 2010;101:75-96. Available from: https://dx.doi.org/10.2528/pier09081805.

21) Deslandes D, Wu K. Integrated microstrip and rectangular waveguide in planar form. IEEE Microwave and Wireless Components Letters. 2001;11(2):68-70. Available from: https://dx.doi.org/10.1109/7260.914305.

22) Lee HY, Jun DS, Moon SE, Kim EK, Park JH, Park KH. Wideband aperture coupled stacked patch type microstrip to waveguide transition for V-band. Asia-Pacific Microwave Conference. 2006. Available from: https://doi.org/10.1109/apmc.2006.4429440.

23) Li CL, Jin C, Ma HQ, Shi XW. An inline waveguide-to-microstrip transition for wideband millimeter-wave applications. Microwave and Optical Technology Letters. 2019. Available from: https://doi.org/10.1002/mop.32199.

24) Kim YJ, Kwak JH, Song H, Jiang X, Kim JP. Broadband aperture-coupled microstrip line to waveguide transition with loading a vertically mounted strip. Microwave and Optical Technology Letters. 2017;59(4):811-815. Available from: https://doi.org/10.1002/mop.30403. 